\title{
A PREVISIBILIDADE NAS CONDENAÇÕES POR DANOS MORAIS: UMA REFLEXÃO A PARTIR DAS DECISÕES DO STJ SOBRE RELAÇÕES DE CONSUMO BANCÁRIAS
}

\author{
Júlia Caiuby de Azevedo Antunes ${ }^{1}$ \\ THE PREDICABILITY OF MORAL DAMAGES LAWSUITS' RESULTS: \\ A REFLECTION BASED UPON STJ' DECISIONS IN
} BANK-CONSUMER RELATIONS

\section{RESUMO}

A PREVISIBILIDADE DO RESULTADO DOS PROCESSOS JUDICIAIS É UMA DAS FACETAS DO PRINCÍPIO DA SEGURANÇA JURÍDICA, PRINCÍPIO ESTE NORTEADOR DO SISTEMA JURÍDICO PÁTRIO. O MÉTODO DO LIVRE arbitramento adotado pelo Código de Processo Civil CONCEDE AMPLA LIBERDADE AOS JUÍZES NA FIXAC̄̃O DO MONTANTE INDENIZATÓRIO POR DANOS MORAIS, O QUE PODE SIGNIFICAR QUE NÃO HÁ COMO PREVER O VALOR CONDENATÓRIO.

POR OUTRO LADO, A JURISPRUDÊNCIA PODE CONTORNAR A IMPREVISIBILIDADE POR MEIO DA UNIFORMIZACCÃ̃O DE SUAS DECISÕES. A TENDÊNCIA EM ADOTAR DETERMINADOS CRITÉRIOS NA QUANTIFICAÇĀO DO DANO MORAL OU EM LIMITAR A INDENIZACÃO À DETERMINADA FAIXA DE VALORES PERMITIRIA UM PROGNÓSTICO DO RESULTADO QUE SERÁ OBTIDO COM A DEMANDA INDENIZATÓRIA, CASO PROCEDENTE.

PAUTADA PELO OBJETIVO DE IDENTIFICAR COMO A OPÇÃO LEGISLATIVA DO LIVRE ARBITRAMENTO É INTERPRETADA E APLICADA PELA JURISPRUDÊNCIA DO SUPERIOR TRIBUNAL DE JUSTIC A, A PESQUISA RESTRINGIU-SE ÀS RELAÇÕES DE CONSUMO BANCÁRIAS, CUJOS VALORES INDENIZATÓRIOS FORAM REVISTOS PELA CORTE ESPECIAL, EM SEDE DE RECURSO ESPECIAL, NO PERÍODO DE OUTUBRO DE 2000 E ABRIL DE 2007.

EM GeRAL, A INTERVEnCão do SUPERIOR Tribunal dE Justiça SE FAZ SENTIR PELA REDUÇĀO SUBSTANCIAL DOS VALORES FIXADOS NAS INSTÂNCIAS ANTERIORES. ASSIM, O PRESENTE TRABALHO TAMBÉM PÕE EM RELEVO A POSSIBILIDADE DE, NA PRÁTICA, HAVER UM LIMITE MONETÁRIO OU TARIFAÇÃO DOS VALORES INDENIZATÓRIOS, NO ÂMBITO DA CORTE ESPECIAL E DE INDAGAR SE O SUPOSTO TABELAMENTO PODE FUNCIONAR, FUTURAMENTE, COMO INIBIDOR DO AJUIZAMENTO DE PROCESSOS JUDICIAIS PELOS CONSUMIDORES LESADOS.

\section{PALAVRAS-CHAVE}

DANO MORAL; CONSUMIDOR; INSTITUIC̣ĀO FINANCEIRA; INDENIZAÇÃO; QUANTIFICACÃO.

\section{ABSTRACT}

THE PREDICTABILITY OF THE LAWSUITS' RESULTS IS ONE OF THE FACETS OF THE PRINCIPLE OF LEGAL CERTAINTY, WICH IS BRAZILIAN LEGAL SYSTEM'S GUIDE. THE METHOD OF FREE QUANTIFICATION adoPTED BY THE CIVIL PROCEDURE CODE GRANTS FREEDOM TO JUDGES WHEN DETERMINING THE MORAL DAMAGES COMPENSATORY AMOUNT, WHAT MAY RESULT IN NOT BEING ABLE TO PREDICT THE INDEMNIFICATION VALUE.

ON THE OTHER HAND, THE COURTS MAY GET AROUND THE IMPREDICTABILITY TROUGH THEIR DECISIONS' UNIFORMIZATION. THE TENDENCY IN ADOPTING CERTAIN CRITERIA IN DAMAGES QUANTIFICATION OR IN LIMITING THE AMOUNT COULD ALLOW LITIGATORS TO FORECAST THE RESULT OF A WINNING JUDICIAL CAUSE. IN ORDER TO IDENTIFY HOW THIS LEGAL OPTION IS INTERPRETED BY THE JUDICIAL SYSTEM, THE PRESENT WORK IS LIMITED TO BANK CONSUMERS RELATIONS, WHOSE AMOUNTS WERE REVISED BY THE SUPERIOR TRIBUNAL DE JUSTICA, FROM OCTOBER 2000 TO APRIL 2007

GENERALLY, THE SUPERIOR TRIBUNAL DE JUSTICCA INTERVENES TO REDUCE THE AMOUNTS QUANTIFIED BY THE INFERIOR COURTS. THEREFORE, THIS WORK HIGHLIGHTS THE POSSIBILITY THAT THE COURT MIGHT ESTABLISH A MONETARY LIMIT OR A "PRICE CONTROL" TO THE MORAL DAMAGES AND INQUIRES IF THE SUPOSED "PRICE CONTROL" MAY WORK AS AN OBSTACLE TO FUTURE CONSUMERS' DEMANDS.

\section{KEYWORDS}

MORAL DAMAGES; CONSUMER; FINANCIAL INSTITUTION; INDEMNIFICATION; QUANTIFICATION. 


\section{INTRODUÇÃO}

O pedido de indenização por dano moral tornou-se parte do cotidiano dos tribunais, uma vez pacificado o entendimento de que a violação de um direito da personalidade, em seu aspecto extrapatrimonial, merece reparação. A indenização por danos morais decorrentes de fato lesivo advindo de relação de consumo, portanto, é plenamente aceita pela doutrina e jurisprudência.

Não obstante a inclusão dos serviços de natureza bancária no campo de incidência do Código de Defesa do Consumidor, ${ }^{2}$ importa ressaltar que nem toda atividade bancária pode ser enquadrada como relação de consumo, e sim como uma relação de natureza estritamente comercial. A presente pesquisa cuida somente de atividades bancárias abrangidas pelo regime especial de defesa do consumidor.

Considerando que as relações bancárias são um palco propício ao surgimento de lesões aos consumidores, toca à presente pesquisa estudar a questão do valor indenizatório do dano moral em citadas relações. Indaga-se se a adoção, pelo ordenamento brasileiro, do sistema de livre arbitramento do valor indenizatório do dano moral, sem o estabelecimento claro de critérios ou limites, resulta na imprevisibilidade do valor da condenação. A existência de uma ampla gama de critérios e teorias que podem ser aplicados para o arbitramento do valor da indenização e a liberdade franqueada para a escolha dos fundamentos que cada juiz entende como justos e razoáveis pode resultar em condenações simbólicas ou milionárias. Inserido neste cenário, o Superior Tribunal de Justiça tem à sua frente a tarefa de harmonizar os valores condenatórios díspares dos tribunais pátrios.

\section{i Recorte da PeSQUisa}

Como "em um debate, as generalidades oferecem a vantagem da simplicidade e da fluidez dos raciocínios, de sua compreensão fácil e, por conseguinte, de maior impacto sobre os ouvintes" (PAGE, 2005, p. 61), houve a restrição dos temas selecionados para avaliar a tendência no Superior Tribunal de Justiça. Buscaramse assuntos de elevada incidência e que tratam de condutas que lesionam o mesmo direito da personalidade (no caso, a honra), o que diminui a possibilidade de as diferenças nos números encontrados resultarem de atribuir maior ou menor valor a um determinado bem jurídico. Escolheram-se os julgados relacionados a: (i) inscrição indevida em cadastro restritivo de crédito; (ii) manutenção indevida do nome do autor em cadastro restritivo de crédito; e (iii) devolução indevida de cheques.

Para a realização do presente trabalho, foi realizada uma pesquisa no banco de dados do site do Superior Tribunal de Justiça (www.stj.gov.br), entre os meses de agosto a dezembro de 2006 e maio e outubro de 2007, a partir de pesquisas com as seguintes palavras-chave: "dano e moral e quantum e indenizatório", "dano e moral e 
inscrição indevida", "dano e moral e indevida e devolução e cheque" e "dano e moral e cadastro restritivo".

Após a leitura das ementas e relatórios dos julgados encontrados como resultado de cada uma das combinações de palavras-chave acima indicadas, selecionaram-se 163 acórdãos. O recorte temporal compreende os acórdãos cuja data da publicação do julgamento encontra-se entre outubro de 2000, quando a corte especial passa a apreciar de forma direta a fixação do quantum indenizatório por danos morais em relação aos temas objeto do presente trabalho, até abril de 2007.

Incluíram-se na análise todos os acórdãos que se referiam a julgamentos de recursos especiais cujo conteúdo estava compreendido no objeto de estudo e que traziam informações sobre os valores indenizatórios em todas as instâncias. Houve o descarte de agravos regimentais, pois, muitas vezes, repetem a discussão de valores já fixados no recurso especial, o que poderia influenciar o resultado da pesquisa, além de poucos casos que não trazem todas as informações relevantes do caso sob iudice. A análise dos julgados foi quantitativa, por meio da identificação dos percentuais em que o Superior Tribunal de Justiça efetuou a revisão da condenação, seja para aumentá-la, seja para diminuí-la.

A diretriz constitucional de motivação das decisões judiciais (artigo 93, IX, da Constituição Federal e artigo 131 do Código de Processo Civil) consubstancia-se na indicação expressa, pelo magistrado, dos motivos conducentes à solução judicial apresentada como adequada ao conflito posto em juízo. A exigência de motivação das decisões judiciais tem por pano de fundo a racionalidade da sentença como pressuposto para o seu controle pelo tribunal hierarquicamente superior (MORAES, 2003, p. 272).

Celso Lafer, ao comentar o significado das obras de Miguel Reale, apresenta uma ideia defendida por este de que "a criação da norma jurídica representa a escolha de uma diretriz de conduta” (LAFER, 2005, p. A2). Não é menos verdade afirmar que, ao aplicar um dispositivo legal, a decisão judicial também refletirá a "escolha de uma diretriz de conduta", ainda mais se a regra contiver um campo de indeterminação a ser preenchido pelo juiz, como ocorre na quantificação do dano moral.

A despeito da obediência ao princípio da motivação, diversas decisões condenatórias não declararam especificamente os critérios adotados no momento da quantificação do dano moral ou os indicam, mas não explicitam o peso que cada um desenvolveu na determinação do valor indenizatório. Ainda que não se conheça a fundo o caminho mental percorrido, está evidente que certas escolhas acerca dos parâmetros para a quantificação foram efetuadas e são aquelas influenciadas pela convicção íntima do órgão judicante, que deve ser exteriorizada na decisão judicial. Ainda que o julgamento não comporte recurso (como, via de regra, ocorre com os recursos especiais), a motivação funciona como garantia do jurisdicionado contra arbitrariedades. A motivação das decisões judiciais, portanto, é essencial para que haja possibilidade real de conhecer os 
critérios adotados na decisão e, assim, ponderar se a escolha está de acordo com a lei ou não, se é justa ou injusta, se merece ou não ser reformada.

Todavia, o que se depara é a ausência de indicação das balizas observada na quantificação da indenização por dano moral. A fundamentação do órgão judicante, ao orientar o comportamento no caso concreto, nem sempre transparece claramente nas decisões da corte especial. A ausência de motivação explícita em grande parte dos julgados dificulta a identificação dos casos em que a variação no valor da reparação é resultado das circunstâncias do caso ou da adoção de critérios diversos para sua quantificação. Assim, o recorte feito também teve por objetivo impedir - ou ao menos limitar - a possibilidade de que tais variáveis (por exemplo, opções teóricas do julgador sobre a função da indenização por dano moral) influíssem no resultado da presente pesquisa.

\section{O SISTEMA BRASILEIRO DE ARBITRAMENTO DO VALOR INDENIZATÓRIO}

A efetiva tutela à dignidade humana ${ }^{3}$ reclama que todo e qualquer dano causado à pessoa seja reparado, independentemente de o prejuízo afetar o patrimônio ou os interesses concernentes ao prisma da essencialidade da condição humana. A partir do princípio da tutela integral da pessoa, a jurisprudência atual é pacífica no sentido de admitir a indenização por dano moral, seja ele cumulado ou não com o pedido de indenização por dano material.

O conceito de dano moral encontra alguma variação na doutrina. Alguns o identificam pela dor, sofrimento, tristeza, angústia, vexame ou humilhação injustificadamente causados. Atualmente, não se enxerga o dano moral como a dor ou sofrimento, que são, na verdade, possíveis consequências ou manifestações advindas da lesão. O dano moral é a violação de interesses reconhecidos pelo sistema jurídico, interesses estes que não são dotados de valor patrimonial intrínseco. O dano moral, portanto, é a afronta a um dos direitos da personalidade.

Regina Beatriz Tavares da Silva destrincha o conceito a partir de dois critérios que distinguem o dano moral do material: a origem e o efeito do dano. Dano moral é aquele cujo prejuízo se origina da violação a um dos direitos da personalidade e que traz como resultado o abalo dos aspectos internos e/ ou externos da personalidade da vítima (SILVA, 2004, p. 258).

O Superior Tribunal de Justiça, ${ }^{4}$ no tocante à prova do dano moral, adota a teoria do fato da violação. Como não há como se adentrar na esfera íntima de sentimentos da vítima para comprovar concretamente o prejuízo, entende-se que o dano exsurge da própria violação a um direito essencial à pessoa humana (BITTAR, 2005, p. 25). Basta a demonstração do comportamento lesivo a um direito da personalidade para que seja reconhecida a existência de prejuízo daí advindo. O dano existe in re ipsa.

Perante a insuscetibilidade de reconstituição específica do bem jurídico prejudicado, em razão da natureza do dano moral, o seu ressarcimento processa-se por meio da 
reparação patrimonial. Não se trata de entregar ao autor da ação o equivalente pecuniário, mas, sim, de lhe atribuir um valor pecuniário como atenuante do agravo suportado.

O pedido do lesado, na ação indenizatória, é o de condenação do autor da violação ao pagamento de uma importância em moeda. O Código de Processo Civil, em seu artigo 286, estabelece a regra geral de que o pedido deve ser certo e determinado. O pedido de indenização por danos morais, entretanto, enquadra-se na ressalva legal, permitida a definição do valor ou quantidade do bem da vida almejado a posteriori. Isto se dá porque não é possível ou recomendável indicar desde logo, na petição inicial, o valor da condenação. A estimativa unilateral pelo autor do valor que entende devido não significa que o magistrado se encontre adstrito à mesma (CAHALI, 2000, p. 694), sendo o valor da causa atribuído pelo requerente visto pela jurisprudência como mera sugestão.

Depara-se o órgão julgador, então, com a tarefa de ponderar o valor devido a título de condenação pela ação contrária ao direito. Entre os extremos da modicidade da indenização e condenações milionárias, o juiz deverá quantificar o dano moral de acordo com o ditado pelo bom senso. Mas o que deve ser entendido como uma condenação justa e razoável? Não fixa a lei, de modo expresso e sistematizado, quais os critérios a serem utilizados na operação de liquidação judicial. Vale dizer, não existem parâmetros seguros e indiscutíveis para auxiliar o julgador a arbitrar o valor a que o dano moral deve corresponder na relação litigiosa posta à sua apreciação.

O artigo 944, caput, do Código Civil dispõe que a indenização é medida pela extensão do dano. Críticas avolumam-se à aplicação deste artigo. Se o dano moral resulta de uma violação a um direito da personalidade e se estes direitos são, fundamentalmente, insuscetíveis de apreciação econômica, a extensão do dano não é medida compatível com sua natureza (SILVA, 2004, p. 262).

Sem embargo, a doutrina e a jurisprudência procuram outros parâmetros de orientação para o arbitramento da condenação. Critérios como o grau de culpa, o nível socioeconômico do autor e do réu, a repercussão do dano, o tempo decorrido entre a conduta lesiva e a propositura da ação, por exemplo, são citados como um guia seguro a nortear o órgão judicante quando do arbitramento da condenação por dano moral. São buscadas ponderações adequadas ao trabalho de quantificação de um valor indenizatório justo. Por justo deve-se entender uma quantia que não seja irrisória, mas que também não represente enriquecimento sem causa do lesado.

O direito à integral reparação dos danos, garantido tanto pela Constituição Federal quanto pelo Código de Defesa do Consumidor, ${ }^{5}$ implica a inexistência de teto indenizatório, isto é, a impossibilidade de se criarem indenizações tarifadas ou de se editarem dispositivos que circunscrevam a reparação a um determinado valor máximo, ${ }^{6}$ a exemplo do que ocorria no Código Brasileiro de Telecomunicações (Lei 4.117/1962) e na Lei de Imprensa (Lei 5.250/1967). 
O sistema do tabelamento ou tarifação é tido como inconveniente porque requer a despersonalização, o que não se coaduna com os princípios da dignidade humana e da isonomia. Ao aplicar a tabela, situações diferentes são tratadas de modo semelhante, visto que não há espaço para a apreciação das peculiaridades do caso concreto. Uma vez afastado o sistema da tarifação pelo ordenamento jurídico pátrio, resta ao magistrado o método do livre arbitramento judicial motivado.

Assente a jurisprudência em que a reparação por danos morais deve ser integral, mas inexistência de balizas legais pode conduzir a distorções na escolha de um ou outro critério pelos juízes na apreciação quantitativa do dano, dificultando uma orientação uniforme do Poder Judiciário. Neste sentido, vale transcrever um extrato do voto da Min. Nancy Andrighi, in verbis:

É da essência do dano moral ser compensado financeiramente a partir de uma estimativa imprecisa com o sofrimento causado, justamente por inexistir fórmula matemática que seja capaz de traduzir as repercussões íntimas do evento em um equivalente financeiro (grifos nossos). ${ }^{7}$

\section{Dano moral no STJ}

\section{I COMPETÊNCIA do STJ E CONTROLE DA QUANTIFICAÇÃo DO DANO MORAL}

Entre as atribuições constitucionais do Superior Tribunal de Justiça está a de julgar, em grau recursal, as causas decididas pelos Tribunais Regionais Federais ou Tribunais dos Estados ou Distrito Federal, com intuito de uniformização da interpretação do direito federal (artigo 105, III, da CF). Ao apreciar o recurso especial, a corte de sobreposição não analisa matéria de fato, mas tão-somente questões de direito. Significa dizer que não há espaço para o reexame de matéria probatória, centrando-se a avaliação judicial na interpretação de dispositivos de lei federal. Tanto é assim que foi editada a Súmula 7: "A pretensão de simples reexame de prova não enseja recurso especial”. ${ }^{8}$

Não obstante o recurso especial não se prestar à apreciação de pontos fáticos controvertidos - e a ponderação sobre a quantia indenizatória é claramente uma questão de fato -, observa-se que o Superior Tribunal de Justiça tem reavaliado a quantificação do dano moral, sob o argumento de que é possível a revisão dos valores condenatórios. Em voto proferido no REsp 826.683/SP, ${ }^{9}$ a relatora Ministra Nancy Andrighi defende a atuação da corte, considerando que, in verbis:

[...] em hipóteses excepcionais, pode o Superior Tribunal de Justiça rever o valor fixado em ação de compensação por danos morais, desde que haja discrepância insuportável com o que ordinariamente se entende por razoável em casos semelhantes. 


\subsection{VALORES Da INDENIZAÇÃo POR DANO MORAL NAS RELAÇÕES DE CONSUMO BANCÁRIAS}

\subsection{MÉdia dos VALORES INDENIZATórios}

A média dos valores indenizatórios demonstra radical variação entre as instâncias inferiores e o Superior Tribunal de Justiça. No universo dos julgados estudados, a média condenatória na primeira instância é de $\mathrm{R} \$ 88.585$,38; na segunda instância, eleva-se para R \$ 105.920,86; e, no Superior Tribunal de Justiça, a média decai vertiginosamente para $\mathrm{R} \$ 12.445,59$. Se somente considerados os valores médios, a redução experimentada no âmbito do Superior Tribunal de Justiça é da ordem de $85,95 \%$ relativamente à quantia fixada na primeira instância e de $88,25 \%$ em relação à segunda instância.

\subsubsection{Manutenção, majoração e fixação pelo STJ}

Em 20,5\% dos acórdãos, a corte manteve a quantia indenizatória, por entender que a fixação observou os padrões de razoabilidade. Nestes casos, a condenação média é de R\$19.964,64, o que não destoa da média encontrada em todos os recursos analisados pelo Superior Tribunal de Justiça. A média dos valores mantidos corresponde a um valor $81,15 \%$ inferior que a média das quantias arbitradas no segundo grau. Observa-se que a corte especial somente mantém as condenações que se encaixam no padrão médio dos valores por ela controlados.

O Superior Tribunal de Justiça procedeu à majoração do quantum indenizatório em somente três dos acórdãos pesquisados (REsp 752.469/RS, REsp 679.248/RJ e REsp 644.236/MG). O aumento foi dado com base no argumento de que a quantia fixada nas instâncias ordinárias mostrou-se como irrisória ou inadequada à lesão sofrida. Há compatibilidade entre os valores finais alcançados nestes casos ( $\mathrm{R} \$ 5.000,00, \mathrm{R} \$ 10.000,00$ e $\mathrm{R} \$ 30.000,00)$ e a média dos valores indenizatórios encontrada no Superior Tribunal de Justiça, que é de R\$ $12.445,59$.

Em 3,68\% dos acórdãos, a fixação da quantia indenizatória deu-se pelo próprio Superior Tribunal de Justiça. São hipóteses em que as instâncias ordinárias julgaram o pedido improcedente, mas a corte especial entendeu como configurado o dano moral. Com o amparo do princípio da economia processual, realizou-se o arbitramento do valor em grau recursal, com vistas às circunstâncias fáticas provadas, variando aquele entre $\mathrm{R} \$ 1.000,00$ e $\mathrm{R} \$ 15.000,00$.

É possível identificar que, quando o Superior Tribunal de Justiça intervém para majorar ou fixar a verba indenizatória, bem como quando mantém o valor da condenação, a corte não se afasta do valor médio das condenações finais. O curso da atuação da corte é, de certa forma, padronizado. Ainda que haja alguma diferença no valor final alcançado, a intervenção do Superior Tribunal de Justiça tem sempre em vista a mesma média de valor. 


\subsubsection{ReduÇÃo No STJ}

No universo pesquisado, o Superior Tribunal de Justiça optou pela redução do quantum indenizatório em 74,23\% dos processos. Tão elevado percentual de revisão indica que o Superior Tribunal Federal percebe os valores arbitrados nas instâncias anteriores como exorbitantes ou desarrazoados, merecendo, portanto, sua diminuição a patamares considerados como adequados.

Uma vez que não existe um cálculo matemático das repercussões negativas da violação, as instâncias inferiores têm liberdade para aferir a quantia devida. A possível ocorrência de exacerbação nas pretensões indenizatórias (STOCO, 2004, p. 1703) ou a chamada "indústria do dano moral", com a consequente banalização do instituto do dano moral, parece ser a principal preocupação do Superior Tribunal de Justiça ao rever o valor indenizatório.

O voto do Min. Sálvio de Figueiredo Teixeira, no julgamento do REsp 265.133, denota claramente tal temor ao afirmar que, "em face de manifestos e frequentes abusos na fixação do quantum indenizatório, no campo da responsabilidade civil, com maior ênfase em se tratando de danos morais, é lícito ao Superior Tribunal de Justiça exercer o respectivo controle". ${ }^{10}$

A corte especial parece não acreditar que a proximidade do juiz de primeiro grau com a realidade fática apresentada no processo lhe empresta melhores condições de aferir o valor adequado ao caso concreto. Em 99,17\% dos casos em que a corte interveio para reduzir a condenação, foi sustentado que o valor era excessivo, o que poderia ser entendido como uma visão de que os julgadores das instâncias inferiores não atuaram com a devida prudência e bom senso na tarefa de quantificação da indenização.

Ao lado da revisão dos valores em quase $80 \%$ dos casos, em regra, para diminuílos, nota-se que há uma aparente padronização dos valores. Ainda que afastem a ideia de tarifação, diversos julgados fazem referência a outros, em que a verba indenizatória é igual ou similar a que se fixa após a redução pela corte especial. ${ }^{1}$

\subsubsection{DistribuiçÃo De Faixas dos Valores CONDENATÓrios}

Na primeira instância, os valores condenatórios variam de R \$ 365,10 a R \$ 900.000,00. $\mathrm{Na}$ segunda instância, há maior oscilação nos valores arbitrados: de R \$1.000,00 a $\mathrm{R} \$$ 4.000.000,00. A discrepância das quantias é impressionante, demonstrando que, nas instâncias ordinárias, não há meio de prever o valor da condenação, tudo a depender, em grande medida, da inclinação teórica do órgão julgador a quantificar indenização por dano moral.

O Superior Tribunal de Justiça não aceita o sistema de tabelamento das indenizações ${ }^{12}$ propugnando pela efetiva reparação dos danos conforme as peculiaridades do caso concreto, o que poderia levar a dissonâncias nos valores encontrados na jurisprudência. Este não é o panorama encontrado na corte especial. Após a revisão dos valores fixados pelas instâncias ordinárias ou manutenção destes, as condenações 
finais são de $\mathrm{R} \$ 300,00$ a $\mathrm{R} \$ 150.000,00$, mas a disparidade não é um elemento que salte aos olhos se levado em consideração o fato de que $64,42 \%$ dos valores finais estão inseridos no intervalo de $\mathrm{R} \$ 5.000,00$ a $\mathrm{R} \$ 30.000,00$.

Não é de considerar a distribuição dos julgados do Superior Tribunal de Justiça como dispersa:

a) 28,83\% dos valores condenatórios são inferiores a R \$ 5.000,00;

b) a grande "fatia" das decisões $(64,42 \%)$ considera valores compreendidos no intervalo de $\mathrm{R} \$ 5.000,00$ a $\mathrm{R} \$ 30.000,00$; e

c) somente $6,75 \%$ inclui valores superiores a $\mathrm{R} \$ 30.000,00$ (sendo o valor mais alto encontrado o de R\$150.000,00, no REsp 291625).

Um dos meios de verificar uma possível padronização de valores é mediante o cálculo do desvio padrão em comparação com a média encontrada em cada uma das instâncias. A identificação do desvio padrão serve para verificar a dispersão dos dados em torno das médias. Segundo Freund, "a dispersão de um conjunto de dados é pequena se os dados estão concentrados em torno da média e é grande se os dados muito afastados da média" (FREUND; SIMON, 2000, p. 61), vale dizer, quanto menor o desvio padrão em relação à média, mais concentrados ou padronizados estão os dados analisados.

$\mathrm{Na} 1^{\mathrm{a}}$ instância, foram obtidos como média e desvio padrão, respectivamente, R \$ 88.585,38 e R \$ 225.307,70, resultando em uma relação de 2,54. No Superior Tribunal de Justiça, foram atingidos os valores de R \$ 12.445,59 e R \$ 16.332,21 para média e desvio padrão, em uma relação de 1,31. Logo de plano se observa que a relação desvio padrão/média é inferior na corte especial, mas, quando analisada em conjunto com a redução da média indenizatória, o resultado é ainda mais expressivo. A redução da média indenizatória $(85,95 \%)$ entre as instâncias analisadas é menor que a redução observada no desvio padrão (92,75\%), a significar que os valores fixados no SJT, além de inferiores, são proporcionalmente mais concentrados que os da $1^{a}$ instância.

O mesmo se verifica ainda mais claramente na $2^{\mathrm{a}}$ instância, na qual a relação desvio padrão/média é de 3,80. A redução da média indenizatória $(88,25 \%)$ entre a $2^{\mathrm{a}}$ instância e a corte especial é menor que a redução observada no desvio padrão $(95,94 \%)$, demonstrando, novamente, que as quantias indenizatórias revistas pelo Superior Tribunal de Justiça são proporcionalmente bem mais concentradas que as da $2^{a}$ instância.

\section{Conclusão}

TABelamento ou UNIFORMiZaÇão de JURISPRUdênCIA PELo STJ?

A adoção do sistema do livre arbitramento da quantia indenizatória pelo ordenamento brasileiro, como consectário do direito à plena reparação dos danos morais sofridos, 
implica a inexistência de prévio limite quantitativo, mas também a ausência de critérios definidos a nortear a tarefa de arbitramento judicial da indenização. Os órgãos julgadores balizam sua atuação em conceitos abertos, como o prudente arbitrio do julgador, o bom senso e a razoabilidade. Tais conceitos indeterminados, todavia, permitem a passagem da cadeia de valores do julgado ao interpretar a norma jurídica.

Tal liberdade concedida aos juízes pode redundar em enormes discrepâncias dos valores obtidos com a condenação judicial. A autorização para julgar conforme suas próprias convicções - ainda que motivadamente - e a ausência de critérios legais, passíveis de controle pelos operadores do direito, formam um campo propício à imprevisibilidade do resultado do arbitramento judicial da indenização por dano moral.

A imprevisibilidade, por sua vez, afeta a segurança jurídica. Não se pode falar em estabilidade social e dos direitos se os detentores do exercício do poder jurisdicional podem conformar de modo muito diferente a quantificação do dano moral de casos idênticos ou muito semelhantes, causando distorções em situações que deveriam receber tratamento igualitário.

Nas instâncias inferiores a variação de valores é considerável (de R \$ 365,10 até $\mathrm{R} \$ 4.000 .000,00)$ e a distribuição dos valores é fragmentarizada, como se depreende do item 3.2.4 supra. No entanto, no âmbito do Superior Tribunal de Justiça, não se percebe significativa variação dos valores finais e a relação desvio padrão/média indica uma concentração dos valores ao redor da média. Pode-se dizer, então, ser possível o prognóstico do valor indenizatório que será alcançado caso a discussão alcance a via recursal especial.

A redução do valor indenizatório é sintomática, sendo observada em mais de 70\% dos casos levados à apreciação do Superior Tribunal de Justiça. A diminuição tende a ser efetivada sem preciso aclaramento de quais elementos do caso concreto foram decisivos para a interferência excepcional da corte, muitas vezes com a mera indicação de que o "valor é excessivo". Nos casos em que houve manutenção do quantum determinado pelas instâncias inferiores, aquele já se encontrava em conformidade com o padrão médio dos valores por ela controlados, conforme observado no item 3.2.2.

A interferência do Superior Tribunal de Justiça no arbitramento do valor condenatório denota a tentativa de conceder valores condenatórios aproximados para situações que cuidam de temas assemelhados, independentemente das circunstâncias de cada caso levado a juízo. Tal constatação leva ao questionamento se, na prática, o Superior Tribunal de Justiça não adotou um "tabelamento" da quantia condenatória, diferentemente do que ocorre nas instâncias inferiores.

Ainda que os julgados do Superior Tribunal de Justiça refutem a ideia de tarifação da indenização, a ausência de indicação das peculiaridades do caso sob iudice que basearam a revisão quantitativa da indenização somada à tendência dos valores condenatórios finais apontada acima servem como indício de que existiria, na prática, um tabelamento da indenização por dano moral nas relações de consumo bancárias. 


\section{INFLUÊNCIAS TEÓRICAS NA QUANTIFICAÇÃO DA INDENIZAÇÃO POR DANO MORAL}

A exposição de motivos do Código de Defesa do Consumidor sinaliza que o diploma legal, ao concretizar a direção dada pela Constituição Federal, teve como norte a justiça e a segurança que devem permear o desenvolvimento econômico-social brasileiro, o que inclui a reparação satisfatória por danos sofridos na relação de consumo.

Com isso, há oscilações de entendimento do que deve ser considerado como o valor justo a reparar o dano moral sofrido, dissonâncias estas que são muitas vezes influenciadas pela teoria adotada quanto às funções da indenização por dano moral.

A despeito da existência de classificações particulares, é possível identificar como três as funções da indenização por dano moral:

(i) compensação, satisfação ou reparação - seria o papel fundamental da indenização. Dada a impossibilidade de retorno à situação anterior, o pagamento em moeda funciona como compensação pela dor ilicitamente infligida, como recompensa pelo desconforto;

(ii) punição ou sanção - imposição de uma reprimenda pelo comportamento lesivo, para que o causador da lesão não se mantenha impune. A sanção revela-se pela diminuição do patrimônio como retribuição pelo mal praticado;

(iii) prevenção, desestímulo, inibição ou sanção indireta - tem por finalidade desestimular o ofensor a repetir o ato lesivo. Ao figurar como advertência de nãoaceitação de comportamento lesivo, a indenização exerce o papel de prevenir futuras ofensas.

Em uma parcela dos julgados, aparece a discussão sobre as funções que a indenização por dano moral deve desempenhar. Pode-se afirmar que a escolha valorativa é refletida na quantificação do dano moral? Por exemplo, os julgados que sustentam que a indenização não pode representar um enriquecimento ilícito, afastando a ideia do caráter punitivo da indenização, adotam um patamar indenizatório inferior àqueles que abarcam a função punitiva da indenização?

Na maioria dos acórdãos, a opção teórica não é apontada de forma clara como critério para fixar o valor indenizatório, daí a dificuldade em aferir qual a relevância de uma ou outra teoria no resultado da revisão de quantias efetuada pelo Superior Tribunal de Justiça. Não obstante não ser esta discussão objeto do presente trabalho, entendemos ser relevante destacá-la como um aspecto interessante a ser incluído em futuras pautas de pesquisa.

\section{Previsibilidade das QUantias INDENIZATóRias E INTERESSE EM DEMANDAR}

Os seres humanos realizam muitas de suas escolhas baseadas em uma ponderação entre "o valor daquilo que se paga (ou usufrui) agora, de um lado, e o valor daquilo que se espera alcançar (ou deverá ser pago) mais adiante, de outro (GIANNETTI, 2005, p. 9). 
Racionalmente, as pessoas abrem mão de algo no presente em razão da expectativa de receber um benefício no futuro. Se a vantagem futura esperada não for atraente o suficiente para se sobrepor ao custo presente, a decisão penderá para o valor mais próximo no tempo.

Quando, perante a possibilidade do ajuizamento de uma demanda, a pessoa lesada está diante das seguintes alternativas: (a) ousar, propondo a ação judicial cabível, para a obtenção, no futuro, da indenização pleiteada ou (b) conformar-se, no momento atual, com o prejuízo experimentando, porém furtando-se do encargo de realizar despesas financeiras com a contratação de um advogado e de assumir o risco de ser sucumbente ao final do processo.

Os valores a serem despendidos com eventuais condenações na esfera judicial fazem parte do custo de produção de qualquer pessoa jurídica. Financeiramente, é razoável afirmar que ao diretor de uma empresa afigura-se como melhor opção o pagamento de um valor de cerca de $\mathrm{R} \$ 12.000,00$, diluídos em anos até a decisão judicial se tornar definitiva e exigível, do que gastar quantias superiores em estudos e implantação de sistemas que alterem seu modus operandi e minimize a ocorrência de defeitos na prestação de serviço ou nos produtos inseridos na cadeia de consumo.

Se o pretenso ofensor conhece antecipadamente o limite quantitativo a que pode ser submetido em uma condenação judicial, poderá avaliar os custos e concluir que, em termos monetários, mais vale a pena infringir a lei do que modificar seu comportamento. Assim, cabe indagar se as condenações fixadas pelo Superior Tribunal de Justiça, após diversos anos de litígio, são um incentivo suficiente para que o agente violador altere seu comportamento.

Ademais, a revisão sistemática dos valores fixados nas instâncias inferiores, com redução em $74,23 \%$ dos casos, aliada ao fato de a média do valor condenatório no Superior Tribunal de Justiça ser drasticamente inferior àquela fixada pelas instâncias ordinárias, podem servir como incentivo às empresas-rés a recorrerem, arrastando a disputa judicial, visto que têm condições de suportar os gastos de um prolongado processo judicial e, ao mesmo tempo, como desestímulo aos consumidores lesados em buscar a via judicial para obter a reparação do dano moral experimentado.

O direito tem como papel primordial estimular comportamentos socialmente desejáveis e tornar desinteressantes condutas indesejáveis. Sem embargo, se o aplicador do direito perder de foco o objetivo pretendido pela norma jurídica protetiva, o direito passa a atuar de modo contrário ao esperado. A indenização por danos morais foi estabelecida como meio de garantir o respeito aos aspectos primordiais da personalidade. Todavia, no momento em que o quantum indenizatório não se mostra como apto a desestimular comportamentos lesivos, a finalidade que a norma procurava proteger se esvai na disputa pela obtenção dos maiores lucros econômicos possíveis.

As decisões judiciais têm vocação para modificar condutas lesivas. A gradual convergência de entendimento na aplicação das normas é medida salutar para resguardo 
da segurança jurídica. No entanto, é importante destacar que a jurisprudência do Superior Tribunal de Justiça, com significativa redução do quantum condenatório fixado nas instâncias inferiores aliada à aparente tarifação da indenização por dano moral, poderá encorajar a reiteração de ofensas pelos fornecedores, se lhes afigurar como financeiramente mais vantajoso o dispêndio de uma quantia não considerável, a título de indenização, ao final da longa duração de um processo judicial. Desse modo, as normas consumeristas perderão seu valor como indutoras de comportamentos desejados e os efeitos persuasivos das decisões judiciais não produzirão os efeitos positivos que poderia ter.

A jurisprudência serve como um dos fatores a serem considerados na escolha pela propositura de uma ação. Observa-se a tendência dos julgados em casos análogos, a fim de identificar a probabilidade de sucesso. Pode ou não ser a jurisprudência um indicador preponderante a levar alguém a litigar em juízo, mas não é menos verdade dizer que é um elemento relevante levado em conta tanto pelo advogado quanto pelo pretenso autor. Ao sofrer um dano moral decorrente da conduta lesiva de um fornecedor de produto ou serviço, o consumidor buscará a via judicial se acreditar como devida a indenização e se for razoável a expectativa de sair ganhador.

Especialmente na jurisdição brasileira, ao lado da incerteza sobre a solução definitiva que será obtida, soma-se a impossibilidade de prever o período de duração do processo até o trânsito em julgado do ato judicial final, sendo conhecido o fato de que os processos judiciais se arrastam por vários anos. Os fatores negativos de tempo prolongado e desconhecimento do resultado podem ser relegados ante o vislumbre de uma indenização em valor significativo adicionada à probabilidade de sucesso na empreitada jurisdicional.

Pode-se afirmar que o número de demandas resolvidas favoravelmente ao consumidor, com a aplicação das normas protetivas, serve como estímulo pela eleição do litígio judicial. Por outro lado, os valores indenizatórios fixados pelo tribunal de superposição em matéria federal podem não se mostrar suficientemente encorajadores se comparados com o que se aguarda como "prêmio" pela longa espera pela indenização.

Do ponto de vista das empresas, a preocupação no cenário econômico atual é de manter ou aumentar as margens de lucratividade. Para que a iniciativa privada atinja seu objetivo dentro do ritmo acelerado da economia, vige, como ressaltado pelo professor José Eduardo Campos de Oliveira Faria, "a lógica do sistema financeiro: o máximo de lucro possível, no menor espaço de tempo, com o máximo de segurança e o menor risco" (FARIA, 2007, p. 18).

O resultado judicial reflete o modo de tratamento de direitos. As decisões judiciais não só atendem ao objetivo primordial de pacificação de conflitos, como também ultrapassam os limites da lide para delinear o caminho a ser trilhado pelos demais componentes do corpo social. No momento em que o quantum indenizatório é percebido pelos ofensores como insuficiente para desestimular o comportamento 
contrário ao direito, a norma não concretiza, no campo fático, a proteção dos sujeitos que visava a resguardar. A finalidade de harmonização de relações intrinsecamente desequilibradas, portanto, não é atingida.

O direito é formalmente aplicado, com a condenação das instituições bancárias que violam o direito à honra dos consumidores. No entanto, o papel de regulador de condutas na direção desejada pode não ser materialmente satisfeito. Cabe indagar se, na prática jurisprudencial cotidiana, o Estado brasileiro tem cumprido a determinação política inscrita na Constituição Federal de 1988 de proteção dos direitos fundamentais da pessoa humana.

: ARTIGO APROVADO (15/09/2008) : RECEBIDO EM 18/03/2008

\section{NOTAS}

1 Especialista em responsabilidade civil pelo GVlaw. Advogada em São Paulo.

2 Cabe destacar a decisão do Supremo Tribunal Federal sobre a incidência do Código de Defesa do Consumidor nos serviços prestados pelas instituições bancárias, conforme o julgamento da ADI 2591/DF em 07.06.2006. Disponível em: <http://www.stf.gov.br/jurisprudencia/nova/pesquisa.asp>. Acesso em: 18 jun 2007.

3 Princípio insculpido no artigo $1 .^{\circ}$, III, da Constituição Federal, como um dos fundamentos da República Federativa do Brasil.

4 Neste sentido: “A jurisprudência desta Corte está consolidada no sentido de que, na concepção moderna do ressarcimento por dano moral, prevalece a responsabilização do agente por força do simples fato da violação, de modo a tornar-se desnecessária a prova do prejuízo em concreto, ao contrário do que se dá quanto ao dano material” (BRASIL. Superior Tribunal de Justiça (4 ${ }^{\mathrm{a}}$ Turma). REsp 602.401/RS, rel. Min. Cesar Rocha, j. 18.03.2004. Disponível em: <http: $/ /$ www.stj.gov.br/SCON/jurisprudencia/toc.jsp?tipo_visualizacao=RESUMO\&livre $=$ dano + moral + quantum + indenizatorio\&b=AC OR>. Acesso em: 30 maio 2007.

5 A plena ressarcibilidade é decorrência lógica da leitura das disposições contidas no artigo $5^{\circ}$, incisos $\mathrm{V}$, $\mathrm{X}$ e XXXV, da Constituição Federal. Mais especificamente em relação às lesões ocorridas nas relações de consumo, o artigo $6^{\circ}$, VI, do Código de Defesa do Consumidor, define como um dos direitos básicos dos consumidores a efetiva prevenção e reparação de danos patrimoniais e morais, sejam eles individuais, coletivos ou difusos.

6 O Código Brasileiro de Telecomunicações cuidava de estipular algumas balizas para a quantificação do dano moral, mas foi revogado antes da promulgação da Constituição Federal de 1988 e da edição do Código de Defesa do Consumidor. A Lei de Imprensa trazia um teto indenizatório de 200 salários mínimos para a reparação por dano moral causado pelos meios de comunicação por ela englobados. Entretanto, o Superior Tribunal de Justiça editou a Súmula 281: "A indenização por dano moral não está sujeita à tarifação prevista na Lei de Imprensa" (BRASIL. Superior Tribunal de Justiça. Súmula 281. Disponível em: <http://www.stj.gov.br/SCON/sumulas/toc.j sp>. Acesso em: 31 maio 2007).

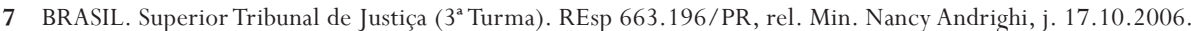
Disponível em: <http://www.stj.gov.br/SCON/jurisprudencia/doc.jsp?processo $=663196 \& \& b=\mathrm{ACOR} \& \mathrm{p}=$ true $\& \mathrm{t}=$ $\& \mathrm{l}=10 \& \mathrm{i}=2>$. Acesso em: 26 out 2006 . 
8 BRASIL. Superior Tribunal de Justiça. Súmula 7. Disponível em: <http://www.stj.gov.br/SCON/sumulas/ toc.jsp>. Acesso em: 31 maio 2007.

9 BRASIL. Superior Tribunal de Justiça. REsp 826683/SP, rel. Min. Nancy Andrighi, j. 16.05.2006. Disponível em: $<$ http: / / www.stj.gov.br/SCON/jurisprudencia/doc.jsp?processo $=826683 \& \& b=A C O R \& p=\operatorname{true} \& \mathrm{t}=\& \mathrm{l}=10 \& \mathrm{i}=1>$. Acesso em: 26 out 2006.

10 Ainda que não trata especificamente dos temas de inscrição indevida em cadastro restritivo de crédito ou devolução indevida de cheque, o caso em julgamento cuida de responsabilidade civil e dano moral, o que é adequado ao objeto da presente pesquisa e denota a preocupação da corte especial. BRASIL. Superior Tribunal de Justiça ( $3^{a}$ Turma). REsp 265.133/SP, rel. Min. Sálvio de Figueiredo Teixeira, j. 19.09.2000. Disponível em: <http://www.s tj.gov.br/SCON/jurisprudencia $/$ doc.jsp?processo $=265133 \& \& b=A C O R \& p=$ true $\& \mathrm{t}=\& \mathrm{l}=10 \& \mathrm{i}=1>$. Acesso em: 26 out 2006.

11 REsp 457734/MT, REsp 331535 /RJ, REsp 442642/PB, REsp 655691 / RS, REsp 790694/RJ, REsp 856296/SP, REsp 705371 /AL, REsp 845416/SP, por exemplo.

12 No voto da Min. Nancy Andrighi, proferido no julgamento do REsp 826683/SP (vide nota 11), é afirmado que o reconhecimento dos excessos e adequação dos valores indenizatórios à jurisprudência do STJ não se trata de uma tendência à tarifação do dano moral, mas, quando necessária a redução de valor discrepante do razoável, adota-se montante próximo de paradigmas da corte. Disponível em: <http://www.stj.gov.br/SCON/jurisprudencia/to c.jsp?tipo_visualiza cao $=$ RESUMO\&livre $=$ dano + moral + quantum + indenizatorio\&b=ACOR $>$. Acesso em: 30 maio 2007.

\section{REFERÊNCIAS BIBLIOGRÁFICAS}

BITTAR, Carlos Alberto. Responsabilidade civil: teoria e prática. 5. ed. Rio de Janeiro: Forense Universitária, 2005. CAHALI, Yussef Said. Dano moral. 2. ed. São Paulo: RT, 2000.

FARIA, José Eduardo Campos de Oliveira. Globalização é um problema, não um destino. Revista Getúlio, São Paulo, ano 1, n. 2, p. 16-23, 2007.

FREUND, John E.; SIMON, Gary A. Estatística aplicada. 9. ed. Porto Alegre: Bookman, 2000.

GIANNETTI, Eduardo. O valor do amanhã. $4^{\text {a }}$ reimpressão. São Paulo: Companhia das Letras, 2005.

GOUVÊA, José Roberto Ferreira; SILVA, Vanderlei Arcanjo da. A quantificação dos danos morais pelo STJ.

Disponível em: <http://www. saraivajur.com.br>. Acesso em: 25 mar. 2007.

LAFER, Celso. Reale aos 95. O Estado de S.Paulo, ano 126, n. 40906, 16 out. 2005. Espaço aberto, p. A2.

MORAES, Alexandre de. Direito constitucional. 10. ed. São Paulo: Atlas, 2006.

MORAES, Maria Celina Bodin de. Danos à pessoa humana: uma leitura civil-constitucional dos danos morais. Rio de Janeiro: Renovar, 2003.

PAGE, Martin. Como me tornei estúpido. Rio de Janeiro: Rocco, 2005.

PEREIRA, Caio Mário da Silva. Instituições de direito civil. Rio de Janeiro: Forense, 2006. 3 v.

SANTOS, Antonio Jeová. Dano moral indenizável. 4. ed. São Paulo: RT, 2003.

SILVA, Regina Beatriz Tavares da. Critérios de fixação da indenização do dano moral. In: DELGADO, Mário Luiz; ALVES, Jones Figueiredo. Questões controvertidas no novo Código Civil. São Paulo: Método, 2004. cap. 11, p. 257-268. STOCO, Rui. Tratado de responsabilidade civil. 6. ed. São Paulo: RT, 2004.

Rua Isabel de Castela, 450, apto. 11

Vila Madalena - 05445-010

São Paulo - SP - Brasil

juliaantunesdagmail.com
Júlia Caiuby de Azevedo Antunes

Especialista em Responsabilidade CiVIL pelo GVlaW AdVogada EM SÃo PaUlo 